\title{
REFLEXÕES SOBRE POLÍTICAS PARA O ENSINO DE ARTES E PRÁTICAS MUSICAIS NAS ESCOLAS A PARTIR DAS CONCEPÇÕES SOBRE MÚSICA E MÍDIA DE PROFESSORES QUE ATUAM NA EDUCAÇÃO BÁSICA
}

\author{
THOUGHTS ON THE POLICIES FOR THE \\ TEACHING OF ARTS AND MUSICAL PRACTICES \\ IN THE SCHOOLS FROM THE CONCEPTIONS \\ OF MUSIC AND MEDIA OF TEACHERS WHO \\ WORK IN THE BASIC EDUCATION
}

Maria José Dozza SUBTIL

Resumo: $O$ trabalho resulta de uma pesquisa realizada de 2000 a 2003 com 48 professores, formados em sua maioria nos cursos de Pedagogia e Letras-Português, que atuavam como docentes em artes na Educação Básica. A pesquisa enfocou prioritariamente a relação mídia e música como estratégia para entender de modo mais detalhado e menos genérico a prática artística na escola. As questões da pesquisa versaram sobre lembranças musicais relacionadas à escolaridade, influência das mídias nas práticas musicais sociais e escolares e o papel da música na escola na visão desses sujeitos. O objetivo foi compreender possibilidades e limites da inserção da arte/música no espaço escolar, tendo em vista a falta de professores habilitados. Nessa perspectiva, o texto resgata algumas políticas para o Ensino de Artes e apresenta autores que refletem sobre a mídia como instituidora de gostos e práticas musicais. Os dados empíricos resultam de questionários com questões abertas e fechadas e entrevistas. Ao final, reflete-se sobre a realidade da arte na escola e sobre a necessidade de implementar

\footnotetext{
* Doutora em Engenharia de Produção - Mídia e Conhecimento - pela UFSC. Professora do Programa de Pós-Graduação em Educação da Universidade Estadual de Ponta Grossa. E-mail: mjsubtil@gmail.com
} 
Reflexões sobre políticas para o ensino de artes e práticas musicais nas escolas...

efetivamente a Formação Continuada dos professores que estão atuando.

Palavras-Chave: Políticas para o ensino de artes. Mídia e educação musical. Formação de professores.

Abstract: This paper is the result of a research carried out from 2000 to 2003, which involved 48 teachers graduated in Languages Course and Pedagogy Course who were teaching at Basic Education as a teacher of Arts. The research focused primary the relationship between media and music as a strategy to deeper understand the practice of teaching arts at school. The research questions considered the musical remembering related to schooling; the influence of the media in the musical, social, and school practices and the role of Arts from the subjects' point of view. The research aims at understanding the limits and possibilities of the inclusion of the art and music in the school context considering the lack of specific trained teachers in this area. In this perspective, the paper retakes some policies to the Arts teaching and presents authors who reflect on the media as an institutive way for enjoying and practicing musical. For the empirical data we applied some open and closed questions and interview. In the conclusion, some reflections on the reality of the arts at school are presented and the needs to effectively implement the continuous teacher training of the practitioners.

Keywords: Policies for Arts teaching. Media and musical education. Teacher training.

\section{INTRODUÇÃO}

A Lei de Diretrizes e Bases da Educação Nacional n 9.394/96, as legislações complementares que se sucederam e os Parâmetros Curriculares Nacionais - PCNs (1997) reconheceram a Arte como área de conhecimento específico e isso constituiu um avanço em relação à "polivalência" (Lei 5692/71) vigente até então. A introdução de 
mais uma linguagem - a Dança - além da Música, do Teatro e das Artes Visuais, sinalizou para a ampliação do trabalho com arte na Educação Básica.

No entanto, historicamente a inserção da arte nas escolas tem enfrentado problemas nas instâncias tanto legais quanto reais. Faz parte do discurso dos gestores afirmarem a importância dessa área para a "formação integral dos educandos", mas essas intenções esbarram na realidade da falta de professores qualificados e de condições materiais efetivas, além, evidentemente, da ausência de uma concepção clara do que seja essa prática.

Objetivando contribuir para esse debate foi realizada uma pesquisa com 48 professores não habilitados, que declararam trabalhar ou já ter trabalhado com arte durante sua carreira docente. A formação assim se distribuiu: Letras/Português 20 (vinte) docentes, Pedagogia 12 (doze), História 6 (seis), Educação Física 5 (cinco), Geografia 2 (dois), Língua Inglesa 2 (dois) e Ciências 1 (um) ${ }^{1}$.

O trabalho enfoca particularmente a relação música e mídia, entendendo-se que esta última se constitui hoje em fonte de fruição e prática estética tanto para alunos quanto para professores (SUBTIL, 2003; 2006). Pretende-se relatar aspectos dessas vivências culturais e refletir em que medida tais práticas se refletem nas percepções desses professores que em algum momento foram responsáveis pelo ensino de arte na Educação Básica ${ }^{2}$.

Antes de mais nada, é necessário esclarecer que essa diversidade de formação dos professores que atuam em arte tem raízes históricas, por força de determinações legais e de concepções de conteúdo e ensino nessa área.

\footnotetext{
${ }^{1}$ A coleta de dados ocorreu em Cursos de Especialização em Educação, os quais sintomaticamente não contavam com professores de artes entre seus alunos. Manifestaram-se 21 professores de dois municípios do Paraná e 17 de dois municípios de Santa Catarina. Grande parte atuava de $5^{\mathrm{a}}$ a $8^{\mathrm{a}}$ séries do Ensino Fundamental e Ensino Médio, concomitantemente. A faixa etária prevalecente era de 30 a 45 anos e a maioria tinha, na época, mais de 10 anos de atuação docente. Quanto ao gênero, foram investigados 42 mulheres e 6 homens.

${ }_{2}^{2}$ Os dados da pesquisa remontam ao período de 2000 a 2003, mas em trabalhos posteriores foi possível detectar que a situação em relação à atuação de professores não habilitados em arte nas escolas continua sem muitas alterações (SUBTIL, 2005, 2007). Importa esclarecer também que outros elementos dessa problemática estão sendo investigados com professores e gestores das escolas, em especial quanto à concepção de arte, formação continuada de professores, áreas artísticas privilegiadas na escola, inserção da arte no currículo e condições necessárias para o ensino de artes.
} 
Reflexões sobre políticas para o ensino de artes e práticas musicais nas escolas...

O Artigo $7^{\circ}$ da Lei $5692 / 71^{3}$ estabeleceu a obrigatoriedade da Educação Artística pela primeira vez nas escolas, propondo um trabalho polivalente com Música, Teatro e Artes Plásticas. A lei propunha integração das áreas em grandes campos de conhecimento: Comunicação e Expressão ${ }^{4}$, Estudos Sociais e Ciências. Essa justificativa sancionou a prática da arte submetida às demandas de outras disciplinas do currículo.

Sob os fundamentos da Psicologia Genética de Piaget, essa "integração" e a assunção da Educação Artística como atividade nas séries iniciais e área de estudo de $5^{\mathrm{a}}$ a $8^{\mathrm{a}}$ séries contribuíram para a redução da arte como campo de conhecimento. Os professores, mesmo com formação numa área artística, eram insuficientes para dar conta da obrigatoriedade proposta pela referida lei. Ressalte-se que a produção e distribuição de livros didáticos com enfoque tecnicista no treinamento de habilidades constituíram-se em recurso para suprir as carências dos professores não habilitados. Assim, os dados sobre a formação dos sujeitos desta pesquisa fazem sentido.

Pode-se perceber a prevalência do curso de Letras na formação dos investigados, e isso decorre de uma proximidade "natural" com a arte no campo da "Comunicação e Expressão", como apregoado pela lei. A fluidez dos campos de conhecimento permitia a troca e partilhas de conteúdos e professores sem muitos problemas. História é uma área que tradicionalmente destina-se ao trabalho com arte, em especial no Ensino Médio (História da Arte), e Educação Física também, por coordenar as tarefas inerentes às festividades e comemorações escolares. A pesquisa demonstra que Pedagogia, por seu caráter de formação genérica dos professores, parece também adequar-se às demandas do ensino de artes.

As questões da pesquisa enfocaram lembranças musicais relacionadas à escolaridade, gosto e preferências em relação à música em diferentes mídias, compositores, intérpretes, grupos musicais, programas de rádio e televisão, espetáculos televisivos e ao vivo; práticas musicais mais apreciadas; a influência das mídias no gosto e preferências musicais; a compreensão do papel da música nas novelas, filmes e propagandas; e a visão de ensino e papel da música na escola.

${ }^{3}$ A partir de 1960 articulou-se a tendência tecnicista na educação brasileira em decorrência do modelo sócio-econômico desenvolvimentista que se implantava no Brasil sob a égide da ditadura militar iniciada em 1964.

${ }^{4}$ Faziam parte da área: Língua Portuguesa, Línguas Estrangeiras e Educação Artística. 
Os instrumentos utilizados para essa coleta foram entrevistas e questionário com questões abertas e fechadas, cujos dados (tabulados e analisados), transformados em itens para efeito de melhor explicitação dos resultados, compõem as considerações aqui desenvolvidas.

\section{MEMÓRIA, GOSTO E CONSUMO MUSICAL}

As recordações musicais da escola relacionam-se ao cantar e ouvir cantigas de rodas, músicas relacionadas às datas comemorativas e hinos pátrios, atividades essas que ficaram na memória de um grande número de professores. Entende-se que tais lembranças musicais estão vinculadas às práticas do "Canto Orfeônico" instituído na década de 30, na ditadura Vargas, por Villa-Lobos, que acentuou a tradição folclórica e popular da música identificado-a com conceitos de coletividade e patriotismo inerentes às festas cívicas, ao folclore nacional e à comemoração de datas do calendário.

A concepção da força socializadora (relação irracional) da música pela ação do canto coletivo (orfeônico) traduz concepções disciplinadoras, sentimento nacional, brasilidade e civismo (SOUZA, 1992) que ainda se fazem presentes nas percepções dos professores.

No entanto, cabe ressaltar que embora a ideologia do Estado Novo possa ser questionada, Villa-Lobos possuía uma profunda percepção da musicalidade brasileira e manifestou a vontade de ofertar a prática musical para todo o povo, via escola.

Os professores pesquisados demonstraram-se consumidores de música através do rádio, da TV e pela compra de CDs e DVDs para consumo doméstico. Os compositores mais nomeados são os clássicos da música popular brasileira, com certo estilo "cult": Tom Jobim, Caetano Veloso, Chico Buarque de Holanda, Djavan, Milton Nascimento e Roberto Carlos (o mais citado). Apesar de menos referenciados, apareceram também Peninha, Roberta Miranda, Renato Russo, Gilberto Gil, Toquinho Tim Maia, João Bosco, Fagner, Geraldo Vandré, Dorival Caymmi, Gonzaguinha, Almir Sater e Cazuza.

É interessante observar que das duplas sertanejas já estabelecidas no gosto popular desde a década de 90, só apareceram Zezé di Camargo e Luciano. Dos conjuntos e grupos musicais, os mais lembrados são os grupos reconhecidos do Rock Nacional: Titãs, Paralamas do Sucesso, Skank, Legião Urbana e Ultraje a Rigor, e dois tradicionais da MPB: Quarteto em Cy e MPB4. Foi insignificante a menção aos conjuntos de pagode e às bandas de axé music. 
Reflexões sobre políticas para o ensino de artes e práticas musicais nas escolas...

Os compositores eruditos, como Beethoven, Bach, Vivaldi, Ravel e Villa Lobos, evocados por muitos, são os clássicos mais veiculados pela mídia televisiva. A variedade de citações mostra que as mídias contemporâneas, através de aparatos tecnológicos sofisticados ao alcance de quase todos, conforme Subtil (2003; 2006), cumprem um papel de socialização dos produtos culturais.

De modo geral, tanto nas entrevistas quanto nos questionários prevaleceu o gosto pela MPB (música popular brasileira de caráter mais elitizado, que se contrapõe à música popular massiva). Quando confrontados com o gosto musical dos alunos, os professores pesquisados revelaram uma aproximação à "legitimidade cultural", ao "bom gosto" e àquilo que foge do "brega" kitsch (ECO, 1976), pelo reconhecimento do valor social atribuído às obras de arte. Há uma transferência do padrão de alta cultura, identificada com a música erudita, para os clássicos acima nomeados. De certa forma, a preferência manifestada a esses compositores mostra um distanciamento das classes populares (a maioria dos alunos), mesmo que no cotidiano a música de massa seja a mais ouvida e mesmo a mais apreciada por todos os sujeitos, na escola e fora dela, como se evidenciou na entrevista. É evidente aqui a manifestação do gosto musical como fator de distinção simbólica.

$\mathrm{Na}$ verdade, cabe explicitar que o que chamamos gosto é um "senso prático (...), esquemas de ação que orientam percepções, escolhas, respostas" (BOURDIEU, 1997, p. 42). Enquanto propensão à apropriação - material e/ou simbólica - de objetos e práticas, está na base do "estilo de vida" e corresponde às diferentes posições (distinção) ocupadas no espaço social, as quais, por sua vez, são uma "retradução simbólica" das diferenças objetivas das condições de existência (ORTIZ, 1983). Isso significa que as escolhas e preferências não estão isentas das origens de classe e da afirmação da ideologia burguesa do "bom gosto", que agrega valor e capital social e cultural.

Em vista disso, cabe-nos evocar o conceito de cultura que Chauí (1985) apresenta:

Em sentido amplo, cultura é o campo simbólico e material das atividades humanas (...) em sentido restrito, isto é, articulada à divisão social do trabalho, tende a identificar-se com a posse de conhecimentos, habilidades e gostos específicos, com privilégios de classe, eleva à distinção entre cultos e incultos . (p.14) 


\section{A MÚSICA NA MÍDIA - REFLEXÕES SOBRE O CONTEÚDO MIDIÁTICO}

Este item revela a contradição no trato das questões midiáticas, particularmente no concernente à música. Mais da metade dos professores (26) afirma que não é influenciado no seu gosto musical pelas emissões televisivas, porém 22 pessoas entendem que são e consideram o poder de divulgação e a persuasão pela repetição como os fatores mais prováveis dessa influência.

As respostas evidenciam a compreensão da relação entre som e imagem como determinante para a formação do gosto: o contexto da televisão (audiovisual), o ato de ouvir o som e associar com uma ima$\mathrm{gem}$, a relação com as novelas (provavelmente com os personagens), $o$ uso da sensualidade como fator de atração das musicas principalmente para os mais jovens e a apresentação constante de novos intérpretes.

Muitos professores não admitem a interferência midiática nas suas escolhas musicais, assim justificando seu posicionamento: porque não me deixo levar pela mídia; meu gosto já está formado; gosto de música desde a infância; tive sugestão dos pais, em casa; sei do que gosto e não me influencio por modismos, etc.

Apesar de não terem sido citados como preferência anteriormente, os programas de auditório e, em especial, os veiculados aos domingos, novelas, canal MTV e filmes são os principais emissores de músicas do agrado dos entrevistados. É interessante observar que, apesar de a maioria afirmar que não assiste novelas, nesse momento muitos as consideram como importante veículo de apreciação musical.

Analisando as respostas, percebe-se que muito do que os professores citam como "gosto autônomo" tem influência da exposição, ainda que temporária, na TV e nas rádios. Por exemplo: a veiculação de uma determinada música como tema de novela ("Como vai você"), de um compositor re-gravado (Peninha), ou de uma composição erudita num comercial ("Quatro Estações" - Vivaldi).

Babin e Kouloumdjian (1982) apresentam a idéia de que o audiovisual, graças aos recursos da eletrônica, trabalha com som/ imagem/palavra numa dimensão ampliada e multiplicada, como "experiência global unificada" (p. 41). Nesse mesmo sentido, Mcluhan (1989), Kerckhove (1997) e Ferrés (1998) falam sobre uma cultura "audiovisual" que espetaculariza a realidade e está (in)formando os sujeitos com novos modos de apreender os objetos culturais. 
Reflexões sobre políticas para o ensino de artes e práticas musicais nas escolas...

Com as palavras transcritas a seguir, Almeida (1994, p. 16) reforça tal idéia:

A transmissão eletrônica de informações em imagem-som propõe uma maneira diferente de inteligibilidade, sabedoria e conhecimento, como se devêssemos acordar algo adormecido em nosso cérebro para entendermos o mundo atual, não só pelo conhecimento fonético-silábico das nossas línguas, mas pelas imagens-sons também.

Nesse sentido, o som das telenovelas (especialmente a música que identifica cada personagem), é (re)apropriado pelos telespectadores e usado como forma de leitura, conhecimento e vivência do/ no mundo (SALINAS ,1994). Essa informação foi confirmada pelos entrevistados.

Em relação à importância da música nos principais objetos midiáticos - propagandas, novelas e filmes - todos são unânimes em afirmar que ela é fundamental na promoção da emoção, caracterizando os personagens, valorizando as cenas e dando o tom: suspense, tristeza, alegria, romance. Evoca-se a imagem pela música: sem música não há história, a cena fica vazia. Para os sujeitos, a função da música é expressiva, estimula a sensibilidade, cria expectativas, propicia identificação com os personagens e promove lembranças.

Há, por parte dos entrevistados, ênfase significativa nessa função expressiva, de caráter intuitivo e emocional da música, que se traduz na visão de que a experiência estético-musical tem a ver mais com uma emoção a ser experienciada e menos com um saber a ser (re)elaborado e compreendido.

A grande maioria considera o que aí está como repetitivo $e$ de baixa qualidade; só o que o povão gosta; manipula a ingenuidade, explora a sensualidade; interesse é mais comercial do que com a qualidade, a crítica, a diversidade e promoção da cultura do povo. Alguns, no entanto, avaliam positivamente o que "aí está", afirmando que há maior diversidade musical. Todavia, poucos têm clareza quanto às possibilidades e limites educativos em relação às mídias, e menos ainda consideram que esse é um conteúdo a ser escolarizado.

Assim, faz sentido indagar em que medida o conteúdo midiático, embora presente na realidade dos alunos e dos professores, está sendo refletido e discutido na escola, seja em arte ou em qualquer outra área de conhecimento. 


\section{A MÚSICA PRATICADA NA ESCOLA}

Pelos relatos, as práticas musicais utilizadas na escola e na sala de aula são variadas: dança/estudo de música em inglês para aprender a língua, exercícios rítmicos, movimentos corporais, teatro, interpretação de letras, paródias e audição de músicas populares e folclóricas para exploração do texto e interpretação. Muito citadas são as festividades e comemorações das datas cívicas.

O que se evidencia, de modo geral, é a utilização da música como "pretexto" para outras atividades em diferentes disciplinas e não como "texto", ou seja, um conhecimento em si, obviamente por falta de formação específica e também por uma concepção da arte em geral como secundária em relação aos "conteúdos escolares", com função decorativa, uma terra de ninguém cujo acesso exige apenas um pouco de sensibilidade.

Tal visão tem como decorrência práticas musicais de caráter terapêutico - para acalmar, concentrar, relaxar, tornar a aula mais agradável; como fundo musical para dinâmicas de relacionamento e convivência. Na concepção dos entrevistados, os aspectos emocionais evocados pela música aparecem como objetivos fundamentais: desenvolver a emoção, a afetividade entre professor e aluno, a sensibilidade, criatividade, expressão, espontaneidade, concentração, disciplina, reflexão, etc. Acentua-se um caráter transcendente, de auto-ajuda, para falar da música na escola como fator de paz, tranqüilidade, fazer pensar na vida, formar o caráter.

Quanto à explicitação do papel que a música deve exercer na escola, de maneira geral aparecem as idéias de: ampliar os conhecimentos através da audição de diferentes tipos de músicas, relação com as outras disciplinas e contextualização. Nesse sentido, alguns entrevistados demonstram preocupação com a inserção da cultura dos alunos no espaço escolar através de propostas sistemáticas incluídas no currículo.

Importa aqui lembrar a concepção de cultura como produção humana datada e situada num dado contexto histórico econômico e social. Tal visão exige maior conhecimento e reflexão sobre os saberes musicais das crianças e adolescentes hoje, pelo aporte das tecnologias que ampliam ao infinito as possibilidades de acesso, fruição e gosto.

De maneira geral todos apontam para a necessidade de resgatar essa linguagem, não tanto como conteúdo em si, como um conhecimen- 
Reflexões sobre políticas para o ensino de artes e práticas musicais nas escolas...

to específico que supõe planejamento, trabalho técnico e avaliação, mas como elemento importante na melhoria das relações e do clima dentro da escola. Assim, a linguagem artística acaba assumindo um caráter de "música de fundo" semelhante ao de "papel de parede"; está presente, mas ninguém percebe.

Apesar da manifestação generalizada quanto à "baixa qualidade das veiculações midiáticas", todos os pesquisados têm consciência da presença onisciente das músicas veiculadas em momentos informais como recreio, festas e apresentações, por opção e seleção não só dos alunos, mas dos próprios professores. Importa refletir, ao final, sobre essa questão.

\section{CONSIDERAÇÕES FINAIS}

Os professores pesquisados são consumidores de música e compram CDs, mais do que livros ${ }^{5}$. Foi possível perceber que, no discurso, a maioria apresenta um gosto musical que contempla os clássicos da Música Popular Brasileira, contrapondo-se ao gosto dos alunos, o qual, na visão dos professores, é mais afinado com o padrão massivo: axé pagode, funk. O conceito de "música de qualidade" está construído a partir da idéia que se tem na sociedade do que seja culto, inculto, de bom gosto ou mau gosto e isso parece ser, em parte, distintivo de classe, tal como preconiza Bourdieu (1998).

No entanto, os dados coletados mostram que, como não poderia deixar de ser, esses sujeitos também consomem (e com prazer!) objetos culturais de caráter massivo. O que se apregoa é a reflexão sobre o preconceito, subjacente nas manifestações desses professores, contra a música das periferias e das classes menos favorecidas. Faz-se necessário conhecer e situar as diferentes manifestações culturais sejam populares, eruditas ou massivas - como processos e produtos humanos produzidos sob imperativos da sociedade de consumo, mas também como forma de resistência e protesto.

Cabe ressaltar que todos apontam a urgência de resgatar a música no interior do espaço escolar e destacam a importância dessa linguagem, embora sem clareza quanto ao "o que", o "como fazer"

5 Dados da pesquisa mostram que os sujeitos compram de cinco a dez CDs por ano e não mais de dois a cinco livros. 
e o "para que" das práticas musicais. Isso encaminha a discussão para a necessidade não só de professores específicos, mas também de formação para todos os docentes que trabalham com adolescentes, em particular, para os quais esse é um conteúdo vivencial de extrema validade.

Há um caminho a ser trilhado na vivência de um conhecimento musical significativo no interior da escola, tanto para os professores quanto para os alunos. A questão fundamental é a que sempre se coloca - formação dos professores: seja como sujeitos apreciadores, fruidores de música e das mídias em geral; seja como educadores, isto é, profissionais com um papel social determinante de transmitir/construir conhecimentos significativos em todas as áreas com os educandos, particularmente os das classes populares. O problema é estabelecer “quem educa os educadores?" usando uma expressão de Marx.

Partindo do princípio de que os professores que temos são esses que aí estão e de que não poderemos contar, pelo menos em curto prazo, com profissionais especializados nas diferentes linguagens artísticas para dar conta da demanda em todos os segmentos da escolarização básica, entende-se que nas artes em geral e na música em particular é possível trabalhar em duas frentes. Em primeiro lugar, esse trabalho deve acontecer nos cursos de Pedagogia (e equivalentes), com a introdução de módulos de Educação Musical que permitam uma vivência básica de conteúdos musicais por parte dos professores generalistas das séries iniciais. Entretanto, como isso é insuficiente, advém daí a segunda frente: Educação Continuada no sentido literal do termo, isto é, educação que se faça ao longo do tempo, por meio de projetos das instituições empregadoras (escolas, redes públicas municipais, estaduais e rede privada), em parcerias com as Instituições de Ensino Superior e com entidades da sociedade organizada que trabalhem com música (fundações, associações de artistas, bandas etc.). Nesse trabalho, é importante considerar - entre outros conteúdos musicais - os objetos culturais midiáticos que aí estão para serem compreendidos e aprendidos de forma criativa em suas possibilidades educativas.

Após o levantamento realizado é pertinente apresentar uma indagação de Vitor Paro (2001, p.35):

Como levar os grandes contingentes de alunos a valorizar as artes, por exemplo, se a escola em que estudam não dispõe dos mínimos recursos para esse fim, e se sua convivência se dá com educadores 
Reflexões sobre políticas para o ensino de artes e práticas musicais nas escolas...

que, também em suas vidas escolares e em sua formação acadêmica, pouco ou nada aprenderam a esse respeito, e cujas condições de vida, até pelo baixo salário que ganham, e pelo ínfimo tempo de lazer que dispõem, os privam permanentemente do contato com qualquer manifestação artística?

A valorização das artes nas escolas implica, sobretudo, vontade política e empenho das instituições e sujeitos responsáveis pelas ações educacionais nessa área. Caso contrário permanecerá a situação atual, em que é possível constatar a música como presença intensa no cotidiano das crianças e professores, e ausência enquanto conhecimento formal, sistemático e significativo, do cotidiano da escola.

\section{REFERÊNCIAS}

ALMEIDA, M. J. Imagens e sons: a nova cultura oral. São Paulo: Cortez, 1994.

BABIN, P.; KOULOUMDJIAN, M. F. Os novos modos de compreender: a geração do audiovisual e do computador. São Paulo: Edições Paulinas, 1982.

BOURDIEU, P. Razões práticas: sobre a teoria da ação. 2.ed. Campinas: Papirus, 1997.

- La distincion: criterios y bases sociales del gusto.Buenos Aires:Taurus, 1998.

BRASIL. Secretaria de Educação Fundamental. Parâmetros curriculares nacionais: arte. Brasília: MEC/SEF, 1997.

CHAUÍ, M. Conformismo e resistência: aspectos da cultura popular do Brasil. São Paulo: Brasiliense, 1985.

ECO, H. Apocalípticos e integrados. São Paulo: Editora Perspectiva. 1976.

FERRÉS, J. Televisão subliminar: socializando através de comunicações despercebidas. Porto Alegre: Artes Médicas, 1998.

KERCKHOVE, D. de. A pele da cultura: uma investigação sobre a nova realidade eletrônica . Santa Maria da Feira: Relógio D’Água Editores, 1997.

MCLUHAN M. Os meios de comunicação como extensões do homem. 5. ed. São Paulo: Cultrix, 1989.

ORTIZ, R. (Org.). Pierre Bourdieu: sociologia. Gostos de classe e estilos de vida. São Paulo: Ática, 1983. 
PARO, V. H. Políticas educacionais: considerações sobre o discurso genérico e a abstração da realidade. In: DOURADO, L. F.; PARO, V. H. Políticas públicas e educação básica. São Paulo: Xamã, 2001. p. 29 - 47.

SALINAS, F. de J. O som na telenovela - articulações som e receptor. São Paulo, 1994. Tese (Doutorado em Educação) - Programa de Pós-Graduação da Universidade de São Paulo - FE-USP.

SOUZA, J. Funções e objetivos da aula de música vistos e revistos: através da literatura dos anos trinta. Revista da ABEM, Florianópolis, n. 1, v. 1, p. 12-21, 1992 .

SUBTIL, M. J. A apropriação e fruição da música midiática por crianças de quarta série do ensino fundamental. Florianópolis, 2003. 227 f. Tese. (Doutorado em Engenharia de Produção) - Programa de Pós-Graduação em Engenharia de Produção, Universidade Federal de Santa Catarina.

SUBTIL, M. J. D.; SILVA, N. J. R.; ATHAYDE, L. M. R.; FREITAS, F. Cadê a arte daqui? Políticas educacionais e práticas artísticas na educação escolar. In: VI JORNADA DO HISTEDBR. 2005, Anais..., Ponta Grossa: Universidade Estadual de Ponta Grossa/UEPG, 2005.

SUBTIL, M. J. D. Música midiática $\mathcal{E}$ o gosto musical das crianças. Ponta Grossa: Editora UEPG, 2006.

. Formação de Licenciandos em Música: o estágio curricular em questão. In: XVI ENCONTRO ANUAL DA ABEM. 2007, Anais..., Campo Grande: Universidade Federal de Mato Grosso do Sul, 2007.

Encaminhado em: 08/07

Aceito em: 03/08 